\title{
O PLANEJAMENTO DA LICITAÇÃO E SEU IMPACTO NA EFICIÊNCIA E NA ECONOMICIDADE DO PREGÃO ELETRÔNICO PARA REGISTRO DE PREÇOS
}

\author{
A. M. CAVALCANTE ${ }^{1}$ e L. G. SANTOS \\ Instituto Federal de Educação, Ciência e Tecnologia do Rio Grande do Norte \\ cavalcante.andrey@gmail.com; luciana.santos@ifrn.edu.br \\ Artigo submetido em 26/07/2018 e aceito em 01/08/2018 \\ DOI:10.15628/empiricabr.2018.7550
}

\section{RESUMO}

A fase interna da licitação surge como etapa na qual verifica-se a possibilidade da adoção de medidas como a realização de levantamento criterioso das quantidades mínimas e máximas a serem adquiridas, a descrição adequada do objeto e a elaboração da pesquisa de preços. Destaca-se, nesse contexto, a fase de planejamento da licitação dentre os processos que apresentam elevado potencial para a implementação de melhorias. Assim, o presente estudo busca avaliar o impacto do planejamento da licitação na eficiência e na economicidade do Pregão Eletrônico para Registro de Preços. 0 trabalho aponta que o planejamento do pregão eletrônico gera reflexos significativos sobre os preços praticados pelos licitantes e, portanto, pode comprometer a eficiência e a economicidade. 0 presente estudo foi viabilizado por meio de entrevistas e pesquisas em fontes bibliográficas para a coleta de dados. Através dos resultados foi possível identificar e ampliar o entendimento sobre as práticas adotadas no processo de compras públicas de uma organização militar. Dessa forma, o representante do setor solicitante, o licitante e o agente de controle interno forneceram narrativas, de acordo com o papel desempenhado por cada parte no contexto do processo licitatório, que evidenciaram a necessidade de implementação de melhorias na fase interna da licitação. Dessa forma, pretende-se fornecer novas possibilidades para o aperfeiçoamento do processo licitatório e proporcionar a redução de custos nas aquisições do setor público.

PALAVRAS-CHAVE: Planejamento, Licitação, Pregão Eletrônico, Eficiência, Economicidade

\section{THE PLANNING OF THE BIDDING AND ITS IMPACT ON THE EFFICIENCY AND ECONOMICITY OF THE ELECTRONIC PROCUREMENT FOR PRICE REGISTRATION}

\section{ABSTRACT}

The internal phase of the bidding comes as a step in which the possibility of adopting measures such as the careful selection of the minimum and maximum quantities to be acquired, the proper 


\section{ISSN - 2447-178X}

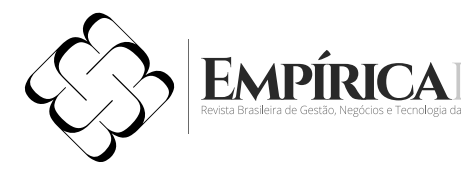

description of the object and the elaboration of the price survey are verified. In this context, the planning phase of the bidding process is highlighted among the processes that present high potential for the implementation of improvements. Thus, the present study seeks to evaluate the impact of bidding planning on the efficiency and economicity of the Electronic Bidding for Price Registration. The study points out that the planning of the electronic trading session generates significant reflexes on the prices practiced by the bidders and, therefore, can compromise the efficiency and the economicity. The present study was made possible through interviews and bibliographic sources for data collection. Through the results it was possible to identify and broaden the understanding of the practices adopted in the public procurement process of a military organization. In this way, the representative of the requesting sector, the bidder and the internal control agent provided narratives, according to the role played by each party in the context of the bidding process, which evidenced the need to implement improvements in the internal phase of the bid. In this way, it intends to provide new possibilities for the improvement of the bidding process and to provide the reduction of costs in the acquisitions of the public sector.

KEYWORDS: Planning, Bidding, Electronic Auction, Efficiency, Economicity

\section{INTRODUÇÃO}

Os órgãos públicos desenvolvem atividades de interesse da população e a oferta regular dos serviços públicos representa preocupação para os gestores, pois a ausência de tais serviços gera reflexos significativos para o bem-estar da população. A prestação dos serviços por parte do Estado depende da aquisição de diversos materiais, bem como da contratação de serviços complementares. Assim, a regra geral para a aquisição de bens ou contratação de serviços para o funcionamento das organizações públicas é a licitação, sendo admitidas pela legislação a dispensa ou inexigibilidade de licitação em casos específicos.

A lei no 8.666, de 21 de junho de 1993, regulamenta o Art. 37, inciso XXI, da Constituição Federal, o qual define que "as obras, serviços, compras e alienações serão contratados mediante processo de licitação pública que assegure igualdade de condições a todos os concorrentes". Além disso, o art. 37 "caput" da Constituição da República Federativa do Brasil de 1988 apresenta expressamente os princípios norteadores de toda a Administra Pública, a saber: "A administração pública direta e indireta de qualquer dos Poderes da União, dos Estados, do Distrito Federal e dos Municípios obedecerá aos princípios de legalidade, impessoalidade, moralidade, publicidade e eficiência".

A Constituição Federal declara expressamente a necessidade de utilização dos recursos públicos disponíveis de forma eficiente e econômica. A Lei Geral de Licitações, como parte integrante do ordenamento jurídico vigente, também deve refletir tais princípios positivados na Carta Magna. Entretanto, o Tribunal de Contas da União vem identificando diversos processos licitatórios que apresentam distorções, inclusive a ausência do cumprimento de requisitos essenciais como o adequado planejamento das aquisições. Por conseguinte, o gestor, ao utilizar mais recursos do que deveria para atingir determinada finalidade, acaba por comprometer a prestação dos serviços públicos. 


\section{ISSN - 2447-178X}

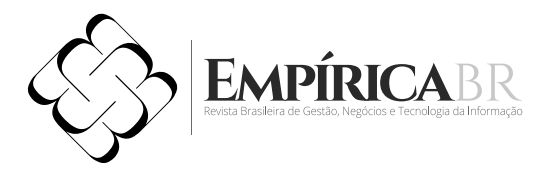

A eficiência no uso dos recursos públicos guarda relação direta com o planejamento das aquisições de insumos e das contratações de serviços. Portanto, o levantamento das necessidades de contratação de serviços e a definição dos quantitativos de bens a serem adquiridos, bem como a regularidade do ressuprimento são informações necessárias para o planejamento das licitações a serem realizadas. Por outro lado, tais informações são essenciais para que os eventuais fornecedores possam elaborar com a devida precisão o dimensionamento das suas propostas no processo licitatório e, posteriormente, realizarem o planejamento dos níveis de estoque necessários para fazer frente aos pedidos conforme os prazos e as quantidades solicitadas pelo órgão público.

Assim, busca-se com a realização do presente trabalho contribuir para o aperfeiçoamento das licitações públicas por meio de propostas de melhorias nos processos da fase interna do certame e, assim, propiciar possíveis maiores níveis de eficiência e economicidade para ambas as partes. Logo, no caso específico dos Pregões para Registro de Preços, espera-se, por meio do planejamento adequado por parte do órgão público, estabelecer o alinhamento entre as necessidades da Administração e a capacidade do futuro fornecedor.

\section{REVISÃO BIBLIOGRÁFICA}

O capítulo da revisão bibliográfica tem como propósito explanar alguns temas que são relevantes ao presente estudo. Em vista disso, será possível compreender os conceitos de planejamento e logística, conforme as atividades que são gerenciadas nas organizações . Duas de tais atividades, nível de serviço e gestão de compras, serão destacadas em uma perspectiva da gestão pública.

\subsection{Planejamento}

Conforme descrevem Gomes e Morgado (2012, p. 295):

A função Planejamento é o ponto de partida para toda ação voltada para resultados, levando a organização a avaliar o futuro e a se preparar para ele. 0 planejamento deve estar presente nas atividades desenvolvidas em todos os níveis hierárquicos, ou seja, no nível estratégico, no nível tático ou intermediário e no nível operacional. Constituise em um instrumento capaz de se antecipar em relação às ameaças e oportunidades futuras, minimizando os problemas no momento presente da organização". (Grifos do autor)

Entretanto, a palavra "planejamento" admite vários outros usos além da definição apresentada anteriormente, que está restrita ao aspecto da função administrativa. Assim, outra aplicação importante do termo ocorre em relação ao chamado "Planejamento Estratégico". Dessa forma, Castor e Zugman (2008, p. 199) assim lecionam: 


\title{
ISSN - 2447-178X
}

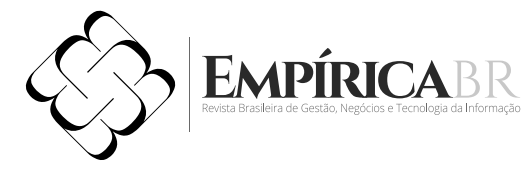

"o planejamento estratégico pode ser definido como o pensamento estratégico aplicado aos recursos e circunstâncias de uma determinada empresa em particular. Tendo compreendido a natureza e a profundidade das mudanças que estão permanentemente ocorrendo à sua volta, uma empresa deve organizar a utilização dos seus recursos para adaptar-se ou antecipar-se às mudanças e tirar proveito delas".

Tratando do mesmo tema, Chiavenato e Sapiro (2010, p. 31) alertam para o seguinte fato:

"O planejamento estratégico está relacionado com os objetivos organizacionais que afetam a viabilidade e a evolução da organização. Mas, aplicado isoladamente, se mostrará insuficiente, pois não se trabalha apenas com as ações mais imediatas e operacionais. É preciso que, no processo de planejamento estratégico, sejam elaborados de maneira integrada e articulada todos os planos táticos e operacionais".

O planejamento, na visão de Kanaane, Fiel Filho e Ferreira (2010, p. 216) surge com a seguinte definição:

\begin{abstract}
"é uma atividade mental, requer criatividade, conhecimento técnico específico na área em que se vai atuar, visão sistêmica da organização para não planejar algo que não se integre ao sistema de gestão como um todo, capacidade de investigação, ousadia, sensibilidade, noção do emprego de recursos financeiros e domínio de técnicas de planejamento".
\end{abstract}

Nesse sentido, cabe destacar que a "noção do emprego de recursos financeiros" e a "visão sistêmica da organização" são requisitos relevantes para o planejamento da licitação, já que os materiais e seus respectivos quantitativos deverão ser solicitados com o máximo de zelo por parte do setor solicitante. Portanto, deve-se considerar a realidade fática quando da elaboração dos pedidos a serem encaminhados para a Seção de Licitações, pois, o objetivo final é suprir o órgão público com os insumos estritamente necessários para a realização de suas atividades sem permitir a criação de estoques desnecessários.

A Advocacia-Geral da União, em seu "Manual de Licitações e Contratações Administrativas", enfatiza os seguintes aspectos do planejamento das licitações (BRASIL, 2014, p. 93):

"O planejamento tem o status de princípio fundamental da Administração Pública desde o Decreto-Lei n 200/67 (art. 6 , I). Também na seara das licitações e contratações públicas deve ser assim considerado, dada a necessidade de os administradores programarem as suas demandas, definirem as prioridades a atender, os recursos orçamentários, materiais e humanos disponíveis, as dificuldades operacionais existentes, as curvas de ressuprimento, as estimativas de custos, entre outros elementos." 


\section{ISSN - 2447-178X}

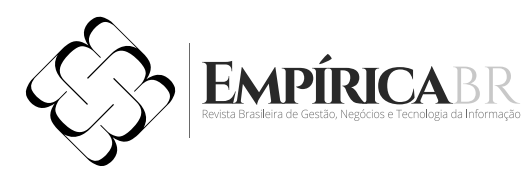

As requisições de suprimento, pelo exposto, devem estar intimamente ligadas ao planejamento estratégico da organização, sob pena de haver ruptura de estoque ou a imobilização de recursos financeiros em estoques desnecessários. Logo, fica envidenciada a necessidade de planejar corretamentes as licitações, inclusive por meio de ferramentas como o calendário de licitações, bem como a realização de estudos para a definição dos materiais a serem adquiridos e as respectivas quantidades previamente estabelecidas por meio de metodologia adequada.

\subsection{Logística e suas atividades}

A origem da logística remonta aos tempos da construção das Pirâmides do Egito e outras grandes obras das civilizações antigas. Entretanto, para outros autores, o surgimento da Logística está nas operações militares de guerra (Faria e Costa, 2015). O conceito adotado pela maior parte dos especialistas foi elaborado pelo Conselho dos Profissionais de Gestão da Cadeia de Suprimentos, pois, contempla todos os aspectos essenciais da Logística, do fornecedor, passando pelo processo produtivo até os consumidores finais (Faria e Costa, 2015).

Assim, Faria e Costa (2015 apud Council of Logistics Management, 2005) apresentam a seguinte definição:

“Logística é a parte do processo da cadeia de suprimentos que planeja, implementa e controla, de forma eficiente e eficaz, a expedição, o fluxo reverso e a armazenagem de bens e serviços, assim como do fluxo de informações relacionadas, entre o ponto de origem e o ponto de consumo, com o propósito de atender às necessidades dos clientes."

O desenvolvimento da logística pode ser compreendido por meio da análise de fatores-chave que proporcionaram saltos de qualidade ao longo do tempo e demarcaram cada fase evolutiva com aspectos que os distinguem de forma notória. Assim, a década de 1950 foi marcada pelo foco no Marketing e a dispersão das funções logísticas por vários departamentos; entre os anos de 1950 e 1960 surgem cargos específicos para o controle do fluxo de materiais e transportes, bem como o conceito de custo logístico total; os anos 1960 a 1970 foram marcados pela evolução dos computadores e pela influência dos fatores de mercado nas empresas, o que fez nascer o conceito de balanceamento de custos logísticos (FARIA e COSTA, 2015).

Nos anos de 1970 a 1980, a tônica foi a redução de custos por meio da integração em prol de um objetivo comum, com foco na eficiência dos processos de armazenagem e distribuição (FARIA e COSTA, 2015). Entretanto, a mudança de paradigma mais relevante foi o surgimento de um novo olhar sobre as necessidades do cliente e o pensamento de integração das diferentes etapas do processo, iniciados na década de 1980, resultantes da evolução da percepção do papel da logística para as empresas e que perduram até os dias atuais com o conceito de Gestão da Cadeia de Suprimentos.

No contexto atual, a Logística Empresarial, segundo Ballou (2015, p. 17), "estuda como a administração pode prover melhor nível de rentabilidade nos serviços de distribuição aos clientes 
e consumidores, através de planejamento, organização e controle efetivos para as atividades de movimentação e armazenagem". Em outra obra, o mesmo autor detalha as atividades da logística em Atividades Primárias e Atividades de Apoio. São Atividades Primárias as seguintes: serviço ao cliente, o transporte, gerência dos estoques e fluxo de informação e processamento de pedidos. Por outro lado, as atividades de apoio apresentam-se conforme o seguinte: armazenagem, manuseio de materiais, compras e embalagem protetora projetada para manuseio e estocagem, cooperação com produção e operações e manutenção das informações (BALLOU, 2006).

Sabe-se que cada cliente possui necessidades específicas. Assim, caberá ao prestador de serviços oferecer soluções que possam contribuir para o sucesso do cliente. Nessa perspectiva, o tratamento individualizado ganha espaço, na medida em que permite o aumento da eficiência e o cumprimento das metas estabelecidos no plano de ação do cliente usuário dos serviços.

Entretanto, o maior nível de diferenciação do serviço implica em maiores custos, notadamente pela dificuldade na distribuição dos custos indiretos e a ampliação dos custos diretos. Dessa forma, o fornecedor precisa conhecer o custo do serviço prestado para não perder oportunidades de diferenciação do nível de serviço.

O nível de serviço logístico, segundo Ballou (2015, p. 73), compreende os seguintes aspectos:

“Nível de serviço logístico é a qualidade com que o fluxo de bens e serviços é gerenciado. É o resultado líquido de todos os esforços logísticos da firma. É o desempenho oferecido pelos fornecedores aos seus clientes no atendimento dos pedidos. O nível de serviço logístico é fator-chave do conjunto de valores logísticos que as empresas oferecem a seus clientes para assegurar sua fidelidade. Como o nível de serviço logístico está associado aos custos de prover esse serviço, o planejamento da movimentação de bens e serviços deve iniciar-se com as necessidades de desempenho dos clientes no atendimento de seus pedidos. " (Grifo do autor)

Na mesma esteira, Faria e Costa (2015, p.134) apresentam a seguinte conceituação:

“O Nível de Serviço ao Cliente está associado ao que se deseja de resposta no próximo elo da cadeia, em termos de disponibilidade do produto/serviço (inventário), confiabilidade do serviço (qualidade) e desempenho (velocidade e consistência das entregas). É algo que está sendo acordado entre comprador e vendedor, onde o comprador faz suas exigências e o vendedor irá verificar a viabilidade de atendêlas, criando valor para ambos. As maiores exigências de níveis de serviço podem requerer maior nível de estoques, pessoal envolvido, sistemas de informação, enfim, determinar maiores Custos Logísticos, com serviços cada vez mais diferenciados. Podemos considerar que o nível de serviço é a maior restrição existente na Logística. " 
Os dois conceitos apresentados anteriormente foram elaborados pelos autores tendo por escopo o setor privado. Logo, faz-se necessário apresentar o mesmo conceito sob a ótica do setor público para uma melhor compreensão do tema. No dizer de Rosa $(2012$, p.18) pode-se obter o seguinte:

"O Nível de Serviço pode ser definido como sendo a qualidade (prazo combinado/ atendido, confiabilidade, integridade da carga, atendimento etc.) na ótica do cliente. Às vezes, face à necessidade de um Nível de Serviço melhor solicitado pelo cliente, este pode aceitar arcar com um custo maior. O Nível de Serviço deve ser estabelecido em contrato antes de se iniciar qualquer atividade, principalmente as atividades logísticas. Portanto, a primeira informação contratual que deve ser estabelecida com o cliente é qual o Nível de Serviço que o cliente deseja comprar. " (grifos do autor)

O conceito em análise, até o presente momento, foi tratado considerando apenas o relacionamento existente entre o órgão solicitante e o seu fornecedor/prestador de serviço externo. No entanto, para Fenili $(2016$, p. 67) o conceito de nível de serviço também deve ser tratado como indicador da gestão de estoque, ou seja, no âmbito interno da organização, conforme segue:

\footnotetext{
"Nível de serviço é um conceito diretamente relacionado aos almoxarifados de uma organização. É um indicador responsável por aferir o percentual de requisições dos demais setores da organização que são atendidas com relação ao total de requisições. " (Grifo do autor)
}

\subsection{Compras governamentais}

As compras governamentais são condição indispensável para a manutenção dos órgãos públicos em perfeito funcionamento. Além disso, as aquisições realizadas pelo Governo movimentam grandes somas de recursos e, pelo uso do poder de compra do Estado, permitem a geração de empregos, o desenvolvimento da indústria nacional e a proteção do meio ambiente pela aquisição de bens com certificação ambiental.

No dizer de Olivo (2011, p.17) "a licitação assume a forma de um procedimento administrativo, regrado por princípios do Direito Administrativo, direcionado à escolha de um eventual contratante." Sendo assim, a escolha da condição mais vantajosa para a Administração Pública deve estar pautada pelos seguintes Princípios Gerais de Licitação: Legalidade, Impessoalidade, Moralidade, Publicidade, Probidade Administrativa, Vinculação ao Instrumento Convocatório e Julgamento Objetivo (OLIVO, 2011, p.18).

As modalidades de Licitação existentes até 1993 eram as seguintes: Concorrência, Tomada de preços, Convite, Concurso e Leilão. Posteriormente, em 17 de julho de 2002 foi promulgada a Lei n. 10.520, que criou a modalidade denominada "Pregão". Deve-se mencionar que as licitações nas modalidades concorrência, tomada de preços ou convite admitem um ou mais critérios de escolha do vencedor, conforme o que segue: Menor preço, Melhor técnica ou Técnica e Preço (OLIVO, 2011) 


\title{
ISSN - 2447-178X
}

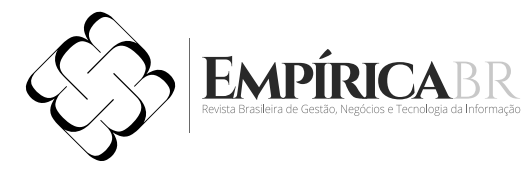

Os princípios básicos de administração pública, conforme estabelece Meirelles (2016, p. 91), "estão consubstanciados em doze regras de observância permanente e obrigatória para o bom administrador e na interpretação do Direito Administrativo". Nesse contexto, o renomado doutrinador aclara que o princípio da eficiência deve ser assim compreendido:

\begin{abstract}
"O princípio da eficiência exige que a atividade administrativa seja exercida com presteza, perfeição e rendimento funcional. É o mais moderno princípio da função administrativa, que já não se contenta em ser desempenhada apenas com legalidade, exigindo resultados positivos para o serviço público e satisfatório atendimento das necessidades da comunidade e seus membros. 0 princípio deve ser entendido e aplicado no sentido de que a atividade administrativa (causa) deve buscar e produzir (efeito) razoável em face do atendimento do interesse público visado (Meirelles, 2016, p. 105)."
\end{abstract}

Diante da definição apresentada, faz-se necessário destacar que o setor de compras e os setores solicitantes possuem o dever de buscar a máxima eficiência durante todo o processo de aquisição e não apenas cumprirem os requisitos legais como mera formalidade. Portanto, como bem apontado pelo ilustre jurista, a função administrativa "já não se contenta em ser desempenhada apenas com legalidade" (MEIRELLES, 2016, p. 105).

O conceito de eficiência, quando inserido no contexto das licitações, recebeu o seguinte parecer de Silva (2008, p. 79) em artigo publicado na Revista do Tribunal de Conta da União:

\footnotetext{
"Ao analisar o Princípio Constitucional da Eficiência (PCE) sob o manto das Licitações Públicas, especialmente nas modalidades de licitação tipo menor preço, constatase o entrelaçamento conceitual entre eficiência e economicidade. Tanto neste como naquele conceito prevalece, entre outras coisas, a ideia de menor custo de aquisição ou contratação, percebido como a diferença monetária entre o valor estimado ou de referência (valor mercado), base para o julgamento das propostas comerciais e o valor homologado pelo Ordenador de Despesas, ou seja, valor efetivamente contratado. "
}

A economicidade é um conceito de suma importância para as aquisições públicas e, sob o prisma do Direito Comparado, foi descrita da seguinte forma por Fernandes (2013, p.63):

"A doutrina estrangeira registra, mas recusa-se a adotá-lo como princípio do direito, recomendando cognominá-lo de 'norma fundamental da economicidade' ou preceito de otimização, considerando que o mesmo não diz o que tem que ser otimizado, mas apenas que deve ser." 


\section{ISSN - 2447-178X}

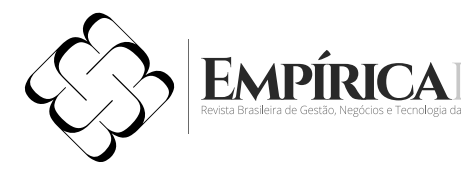

A explanação do jurista é reveladora para o gestor público, pois, ao afirmar que a doutrina estrangeira rejeita a nomenclatura de "princípio da economicidade" sob a justifica de que "o mesmo não diz o que tem que ser otimizado, mas apenas que deve ser" (Fernandes,2013, p.63), acaba por ressaltar a necessidade da atuação do administrador como profissional capacitado para realizar a avaliação e a análise dos processos, principalmente quando estiverem relacionados ao suprimento do órgão público.

Sendo assim, os processos que apresentem possibilidade de otimização deverão ser objeto de revisão por parte do gestor, sempre dentro dos limites da legislação, de forma a torná-los fonte de economicidade, garantindo, assim, a adequada alocação dos recursos disponíveis.

A problematização das diferentes teses existentes sobre o princípio da economicidade nas licitações fez emanar o seguinte questionamento, devidamente tratado na obra de Fernandes (2013, p. 63): “Com frequência, questionam por que esse princípio não foi elencado no art. $3^{\circ}$ da Lei $n^{\circ}$ 8.666/1993 e somente foi referido de passagem em partes da lei? " Seguindo a sua análise, o autor apresenta a seguinte resposta ao questionamento anterior:

\footnotetext{
"A citação expressa do princípio da economicidade ocorre como mero reforço, pois licitar é buscar a proposta mais vantajosa. O princípio da licitação é na verdade corolário daquele princípio, pois visa na essência, à obtenção do menor preço ou melhores condições para a Administração."(Fernandes, 2013, p. 63)
}

O Pregão pode ser conceituado da seguinte forma, segundo o magistério de Fernandes (2013, p. 341):

\footnotetext{
"é uma nova modalidade de licitação pública e pode ser conceituado como o procedimento administrativo por meio do qual a Administração Pública, garantindo a isonomia, seleciona fornecedor ou prestador de serviço, visando à execução de objeto comum no mercado, permitindo aos licitantes, em sessão pública presencial ou virtual, reduzir o valor da proposta por meio de lances sucessivos."
}

A lei no 10.520, de 17 de julho de 2002, instituiu uma nova modalidade de licitação que, segundo Olivo (2011, p.48), "é uma modalidade invertida, pois primeiro se analisa a proposta de preços para depois abrir o segundo envelope, no qual estão os documentos de qualificação do proponente."

As principais características do pregão são a "limitação do uso a compras e serviços comuns", "possibilidade de o licitante reduzir o valor da proposta durante a sessão", "inversão das fases de julgamento da habilitação e da proposta" e "redução dos recursos a apenas um" (Fernandes, 2013, p. $341)$.

O pregão pode ser realizado de forma presencial ou eletrônica. O pregão presencial é tratado pela lei $n^{\circ} 10.520$, de 17 de julho de 2002, já o pregão eletrônico é regulamentado pelo decreto $n^{\circ} 5.450$, de 31 de maio de 2005.

O Pregão eletrônico apresenta as seguintes diferenças em relação ao pregão presencial (Olivo, 2011, p.52): 


\section{ISSN - 2447-178X}

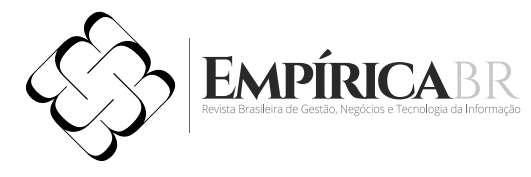

O procedimento é feito a distância, em sessão pública, por meio de sistema que promova a comunicação pela internet; - A autoridade competente, o órgão promotor da licitação, o pregoeiro, os membros da equipe de apoio e os licitantes deverão ser previamente credenciados pela atribuição de chave de identificação e de senha; - dotado de recursos de criptografia e de autenticação uma nova modalidade de licitação pública e pode ser conceituado como o procedimento administrativo por meio do qual a Administração Pública, garantindo a isonomia, seleciona fornecedor ou prestador de serviço, visando à execução de objeto comum no mercado, permitindo aos licitantes, em sessão pública presencial ou virtual, reduzir o valor da proposta por meio de lances sucessivos.; - 0 credenciamento do licitante depende de registro no SICAF; - Não podem ser licitadas obras de engenharia, locações imobiliárias e alienações em geral; - A íntegra do Edital fica disponível no Portal de Compras do Governo Federal - Comprasnet; - O pregoeiro verifica as propostas e classifica aquelas em conformidade com o Edital. Estas, independentemente do valor, participam da fase de lance; - Os licitantes podem oferecer lances sucessivos e, enquanto perdurar a sessão, serão informados, em tempo real, do valor do menor lance registrado, vedada a identificação do licitante; - O sistema eletrônico avisa sobre o encerramento dos lances, que ocorre, aleatoriamente, em até 30 minutos após o aviso; e - Após o encerramento da sessão, o pregoeiro pode encaminhar contraproposta ao licitante vencedor para que seja obtida melhor proposta.

O recente Decreto $n^{0}$ 7.892/2013 define o SRP como "o conjunto de procedimentos para registro formal de preços relativos a prestação de serviços e aquisição de bens, para contratações futuras." O mesmo autor alerta para o fato de que o SRP não representa uma nova modalidade de licitação, mas que a "característica singular, sui generis, dessa concorrência ou pregão é que não obriga a Administração Pública a promover as aquisições" (FERNANDES, 2013, p. 28-30).

Licitação para Registro de Preços, regulamentada pelo decreto n 7.892, de 23 de janeiro de 2013, apresenta inúmeras vantagens para o gestor público, tais como a redução de custos de estoque e o aumento da eficiência. Entretanto, o fornecedor acaba por suportar diversos riscos na operação, já que assume a responsabilidade de fornecer os produtos pelo preço registrado em Ata durante todo o prazo fixado e nas quantidades solicitadas, respeitando-se os limites estabelecidos e os acréscimos e reduções previstos em lei.

A conclusão apresentada pelo doutrinador no trecho citado abaixo revela a razão da existência do Sistema de Registro de Preços (Fernandes, 2013, p. 30):

Sob outro prisma, possível afirmar ainda que o SRP constitui verdadeira garantia para o Administrador que não deixará de realizar a licitação, mas apenas adotará um procedimento especial de licitação - especial, principalmente, por não obrigar a aquisição do produto ou serviço -, previsto em lei, que muito se aproxima da forma de contratação praticada pelo setor privado, um dos princípios vetores da Administração Pública consoante a lei. 


\section{ISSN - 2447-178X}

Pelo exposto, fica evidenciado que, ao adotar o Sistema de Registro de Preços, a Administração Pública busca elevar o nível de eficiência da sua gestão e otimizar a utilização dos recursos públicos.

\section{METODOLOGIA}

A ciência utiliza-se de um método que lhe é próprio, o método científico, elemento fundamental do processo de conhecimento realizado pela ciência (SERVERINO, 2007). Portanto, a metodologia utilizada na pesquisa indica o caminho a ser percorrido pelo pesquisador, bem como confere a validade necessária para o trabalho desenvolvido. Segundo Gil (2008), quanto ao nível de pesquisa, existem as seguintes categorias: pesquisas exploratórias, pesquisas descritivas e pesquisas explicativas.

0 presente trabalho, quanto ao método e à forma de abordar o problema pode ser classificado como pesquisa qualitativa, pois busca atuar diretamente na realidade, inclusive, por meio da coleta dos dados para a adequada compreensão do problema. Além disso, a pesquisa qualitativa possui natureza descritiva, já que "se preocupa com descrever os fenômenos por meio dos significados que o ambiente manifesta" (ZANELLA, 2012, p. 74).

A coleta de dados para a realização das análises que serão apresentadas a seguir foi fruto de entrevistas com o Agente de Controle Interno, com um Chefe de Seção de Organização Militar (doravante denominado "Órgão Público") e com o Sócio-administrador de empresa que venceu uma das licitações da Organização Militar objeto da pesquisa e que, atualmente, é um dos fornecedores do referido órgão público.

As entrevistas ocorreram entre os dias 10 e 13 de setembro na cidade de Fortaleza, Estado do Ceará. Os entrevistados serão identificados apenas como "Licitante", "Agente de Controle Interno" e "Chefe do Setor Solicitante", tendo em vista manter o anonimato dos participantes. Dessa forma, buscou-se apresentar as diferentes percepções sobre as aquisições de materiais por meio de Pregões para Registro de Preço contendo as reflexões, por um lado, de dois representantes do setor público e, de outro, por um empresário representando a visão do licitante.

Assim, quanto ao objetivo da pesquisa, pode-se afirmar que se trata de pesquisa descritiva, pois, conforme leciona Zanella (2012, p. 78), é "um tipo de estudo muito utilizado em Administração Pública, já que se presta a descrever as características de um determinado fato ou fenômeno".

Os procedimentos para a obtenção dos dados serão a pesquisa bibliográfica e a utilização de entrevistas. Nesse sentido, (GIL, 2007 apud Zanella, 2012) comenta a classificação dos procedimentos de coletas de dados em dois grandes grupos, a saber: fontes de "papel", nas quais encontram-se as pesquisas bibliográficas e documentais; e as fontes de "gente", das quais fazem parte a pesquisa experimental, a ex-post-facto, o levantamento, o estudo de campo e o estudo de caso.

Dentro do escopo do trabalho, foram realizadas entrevistas semi-estruturadas como forma de levantamento de informações relevantes para o trabalho. Sendo assim, foram escolhidos 3 (três) entrevistados que pudessem expor as percepções e interesses dos diferentes atores do processo de licitação, conforme a seguinte divisão: o empresário licitante na condição de fornecedor; o chefe de setor de órgão público como responsável pela solicitação de materiais; e o agente de controle interno, como responsável pela garantia da legalidade e conformidade dos atos praticados. 


\section{ISSN - 2447-178X}

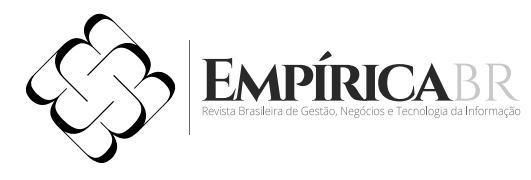

As entrevistas foram conduzidas de forma a abordar os tópicos mais sensíveis para cada uma das partes. Assim, o licitante possui como principais obrigações fornecer os materiais nas quantidades solicitadas, dentro do prazo determinado e pelo preço registrado em Ata. 0 setor solicitante tem por obrigação realizar estudos para determinar as quantidades a serem licitadas conforme as necessidades atuais e as projeções de demanda, bem como definir o preço de referência que servirá de parâmetro para o julgamento objetivo das propostas.

Por seu turno, ao Agente de Controle Interno cabe zelar pela legalidade, eficiência e economicidade dos processos licitatórios. Cumpre ressaltar que serão apresentados os pontos mais relevantes de cada entrevista, de forma a manter a objetividade do presente trabalho sem comprometer a adequada profundidade no tratamento das narrativas. Dessa forma, espera-se compreender os fatores-chave para a ocorrência do fenômeno em estudo, bem como apresentar novas propostas para o enfrentamento das questões abordadas no presente trabalho.

\section{RESULTADOS E DISCUSSÕES}

As informações obtidas por meio das entrevistas possibiliram verificar que existem diversos aspectos passíveis de melhorias nos pregões para registro de preço conduzidos pela organização militar pesquisada. Assim, o planejamento adequado apresenta-se como o primeiro fator relevante para o aumento da eficiência e da economicidade das aquisições do setor público.

O planejamento contempla o levantamento das necessidades e a definição dos quantitativos a serem possivelmente adquiridos. Entretanto, seria possível elevar o planejamento a um novo patamar de excelência com a realização da projeção das quantidades estimadas a cada pedido em conjunto com a frequência de pedido provável, tomando como fonte a série histórica de cada item licitado.

Além disso, observou-se, com base nas informações obtidas dos entrevistados e pelas análises da bibliografia dispinível, que nem sempre o ideal da economia de escala é atingido nas licitações, principalmente no Pregão para Registro de Preços, já que existe um elevado grau de incerteza sobre as reais quantidades de bens que serão efetivamente adquiridos pelo órgão público demandante.

\subsection{Análise da entrevista com o Chefe do Setor Solicitante}

Os custos logísticos são mais um fator relevante na formação de preços. A imprevisibilidade na demanda pode ser em maior ou menor grau a depender da natureza do objeto. Os entrevistados exemplificaram produtos que possuem grande previsibilidade de demanda e, portanto, ampliam a viabilidade de maior precisão na demanda total, na definição dos lotes mínimos e da frequência de pedido.

Atualmente, os órgãos limitam-se a informar o quantitativo máximo a ser adquirido e, após determinação do Tribunal de Conta da União, no âmbito da Administração Pública Federal, também informam o lote mínimo a ser possivelmente adquirido. Porém, para evitar maior detalhamento, os órgãos públicos informam, apenas, que a menor quantidade solicitada a cada pedido será de uma unidade do produto. 


\title{
ISSN - 2447-178X
}

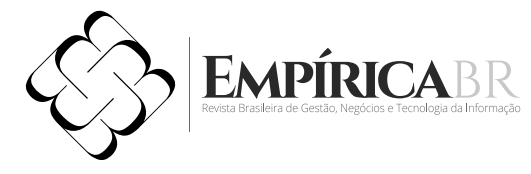

Sobre as aquisições por meio de Pregão SRP e a sua possível relação com a economia ou flexibilidade para o processo de compras o chefe do setor solicitante explanou o seguinte:

\begin{abstract}
"Além da questão da economia também existe a questão da viabilidade, o interessante é que no SRP você vai comprar exatamente aquilo que precisa, sem a necessidade de adquirir quantidades maiores do que realmente vai utilizar. Então, no primeiro momento, não existe uma economia de preço mais barato, mas previne o desperdício e possibilita o gerenciamento do custo de oportunidade, porque o dinheiro será alocado de forma correta e acaba tornando mais flexível o processo de compras. "
\end{abstract}

Sobre os objetivos da gestão de materiais Fenili $(2016$, p. 17) tece as seguintes considerações:

“Suprir a organização dos materiais necessários ao seu desempenho, no momento certo, com a qualidade requerida, praticando preços econômicos, recebendo e armazenando os bens de modo apropriado, distribuindo-os aos setores demandantes, evitando estoques desnecessários e mantendo rotinas de controle efetivas. "

A metodologia utilizada na definição dos quantitativos solicitados foi apresentada pelo chefe do setor como segue:

"A definição das quantidades solicitadas para o Registro de Preços de 2018 estão sendo estimadas com base em cardápios ideais e são projeções das quantidades do ano anterior para o ano seguinte resultantes do cruzamento com o que foi efetivamente consumido. Além disso, eu recebi a orientação para reduzir significativamente o valor total em relação ao ano anterior, embora eu considere isso muito perigoso porque eu não posso prever possíveis mudanças no consumo que possam ocorrer."

O dimensionamento dos estoques foi retratado por Fenili (2016, p. 51), conforme segue:

“A decisão acerca do dimensionamento do estoque de segurança em órgãos públicos é uma tarefa do gestor de estoques, que leva em consideração aspectos tais como: (1) tempo médio de tramitação do processo de aquisição do material, considerando os ritos necessários à condução da licitação; (2) perecibilidade do material; (3) volume do material; (4) impacto financeiro na organização; (5) histórico de óbices na entrega do material, indo desde atrasos por parte de fornecedores, entrega de materiais em desconformidade com as especificações; e (6) flutuação na demanda do material."

O chefe do setor solicitante forneceu os seguintes comentários quando questionado se existem produtos que, pela sua natureza, permitem a formação de estoque e apresentam maior facilidade/ dificuldade de previsão de demanda: 


\section{ISSN - 2447-178X}

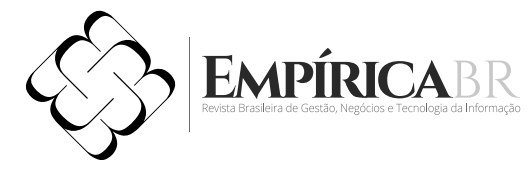

“Essa sua pergunta é muito interessante e reflete bem a realidade do meu trabalho atual na previsão da demanda de 2018. Existem itens sim muito mais fáceis de prever a demanda do que outros. Se eu não estivesse da Seção de Subsistência e estivesse no Almoxarifado Geral, por exemplo, e eu tivesse que falar a demanda, por exemplo, de resmas de papel A4, tenho certeza de que seria muito mais fácil que prever a demanda de tinta, já que esse material não é de uso tão frequente enquanto o outro é utilizado diariamente. Na Subsistência, ocorre a mesma coisa. Todos os dias são consumidos leite, café e suco, independentemente do cardápio. 0 arroz também, é consumido praticamente todos os dias. A couve, por exemplo, é utilizada em cardápios específicos e a sua previsão, no momento de definir as quantidades para o Pregão, é difícil."

A respeito da função compras, (Gonçalves, 2007 apud FENILI, 2016, p. 87) demonstra a complexidade envolvida no processo:

A função compras requer planejamento e acompanhamento, processos de decisão, pesquisa e seleção de fontes supridoras dos diversos materiais, diligenciamento dos fornecedores (para assegurar que o produto será recebido sem atrasos, no momento esperado). Requer, ainda, uma coordenação geral entre os diversos órgãos da empresa: almoxarifados, finanças e todos os diversos setores que são revestidos do papel de clientes da compra a ser realizada.

A indagação sobre a utilidade de uma possível classificação dos produtos conforme as características de durabilidade e estabilidade na previsão da demanda e definição da frequência de pedido ao fornecedor nas licitações foi relatada pelo Solicitante como segue: "Aqui a ideia é trabalhar com suas novas informações, a durabilidade e a previsibilidade da demanda do item no Pregão. Eu entendo que isso seria bom para o fornecedor, para ele criar uma expectativa mais realista do que será solicitado e, então, ele não vai criar uma expectativa falsa. Nesse sentido, entendo que seria muito interessante sim."

A existência de maior flexibilidade no SRP para a manutenção dos estoques foi analisada da seguinte forma pelo Chefe do setor solicitante: "Eu tenho certeza que sim, porque das modalidades de licitação, para a Subsistência, é a única forma que eu vejo possível fazer tudo funcionar de acordo com as nossas necessidades." A resposta sobre a viabilidade de informar no Termo de Referência uma previsão aproximada dos lotes mínimos a serem adquiridos com base em projeções do histórico de consumo e a frequência de pedido foi a seguinte:

"Se eu considerar aqueles itens mais frequentes, uniformes, mais fáceis de prever, entendo ser possível sim pensar em lote mínimo de pedido. Não vão ser muitos itens, mas consigo pensar em alguns da Ata, como a carne, feijão, açúcar, sal, em geral coisas da cesta básica que não podem faltar no estoque e são solicitados ao fornecedor mensalmente." 


\section{ISSN - 2447-178X}

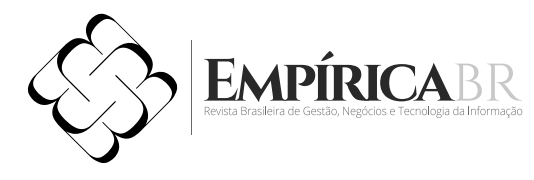

O relato a seguir retrata a visão do Solicitante sobre a ocorrência ou não de problemas relacionados com a entrega de materiais que possam ter relação com o serviço logístico:

\footnotetext{
"Sobre as empresas de outros Estados que participam eu tenho a comentar que existe um certo percalço na logística quando quem quando quem ganha o item é uma empresa de outro Estado, porque, normalmente, quanto mais longe pior. Existem dois casos de empresas de outros Estados que são detentoras de alguns itens da Ata e que demoram mais tempo para entregar, uma que é de Recife e a outra é uma empresa que fornece o gás, que é de Mossoró. Quando solicitamos o gás, não é de uma hora para outra que a gente recebe, somente depois de algumas semanas, mas elas não deixam de fornecer por isso, pelo menos com as empresas com as quais eu tive contato."
}

Sobre a utilização de operadores logísticos por parte dos fornecedores foi relatado o seguinte: "Sobre as entregas dos pedidos, na Seção de Subsistência, a maioria das empresas utiliza veículo próprio para a entrega dos itens." A abertura de processo de punição de empresas pela inexecução ou execução parcial da entrega e a sua frequência foram tratadas da seguinte forma:

"Desde que estou aqui, eu ainda não vi nenhuma empresa ser punida de forma grave, notificada sim, mas para reduzir as ocorrências nós acabamos dialogando com os fornecedores para alinhar as necessidades e evitar problemas. Atualmente, não venho enfrentando problemas com nenhuma empresa."

O chefe do setor solicitante foi enfático quando questionado sobre a possibilidade de existência de uma relação direta entre o serviço logístico e as faltas cometidas pelas empresas:

\footnotetext{
"Sim, se a empresa deixa de entregar, se a empresa atrasa a entrega, isso complica a execução do nosso planejamento, se a empresa deixar de fornecer carne no momento certo, no lugar certo e na quantidade certa eu deixo de ter esse material para fornecer e tenho que pensar em soluções alternativas."
}

\subsection{Análise da entrevista com o licitante}

O empresário entrevistado enfatizou que os quantitativos apresentados nas licitações não refletem as reais necessidades dos órgãos licitantes e, objetivando mitigar o risco de possíveis perdas, são ofertados lances conservadores, que não permitem uma real economia de escala. Sendo assim, os órgãos públicos deixam de exercer seu papel de estimular o crescimento de determinados setores, ao mesmo tempo em que deixam de garantir maior economicidade nas aquisições. 


\title{
ISSN - 2447-178X
}

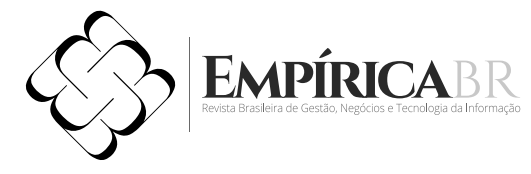

Logo, fica evidenciado que a ausência de um maior detalhamento sobre os quantitativos total e parcial acaba por gerar incerteza para o licitante sobre as reais necessidades do órgão público e, assim, os custos de manutenção de estoques podem ser repassados para o solicitante. 0 licitante relatou que o SRP apresenta, para o empresário, as seguintes vantagens e desvantagens: "Vantagem: Possibilidade de potencializar as vendas através da adesão a ata. Desvantagem: Total incerteza quanto ao que realmente será contratado no transcurso da ARP."

Nesse mesmo sentido, o Tribunal de Contas da União (TCU) apresenta a seguinte diretriz:

\begin{abstract}
“Sem saber quais os quantitativos mínimos e máximos que podem ser praticados em determinado contrato, o fornecedor não tem como elaborar orçamentos com precisão adequada, tendo em vista que não possui elementos para dimensionar os custos referentes a montagem de uma estrutura organizacional que faça frente as possíveis demandas do órgão licitante (BRASIL, 2010, p. 212)."
\end{abstract}

1. O licitante apresentou a seguinte crítica ao comentar o conteúdo das informações fornecidas no Termo de Referência sobre as quantidades a serem possivelmente adquiridas pelos órgãos públicos: "Não consideramos, de modo algum, o quantitativo informado no TR confiável." (Grifamos)

A Corte de Contas foi enfática ao deliberar sobre as quantidades solicitadas pelos órgãos públicos em licitações:

Sem conhecer as faixas de quantidades que podem ser requeridas, o fornecedor não tem como avaliar sua possibilidade de atendimento as solicitações do contratante, o que o leva ou a adoção de valores médios na tentativa de atenuação do risco de apresentar preços não condizentes com as demandas futuras e, diante dessa situação a Administração Pública deixa de obter descontos que poderiam ser ofertados pela licitante consoante as estimativas de demanda (BRASIL, 2010, p. 212)“

O licitante, ao ser solicitado a comentar, com base na sua experiência, sobre se os quantitativos informados pelos órgãos públicos seriam realistas ou mero cumprimento de uma formalidade legal, desenhou o seguinte panorama:

“Não consideramos realista, nem mesmo cumprimento de realidade formal, pois se assim fosse, seriam baseados estudos técnicos preliminares e elementos objetivos, que aproximariam o estimado do realmente contratado, conforme jurisprudência do TCU, como os acórdãos 757/2015 - Plenário, 3.137/2014 - Plenário e 392/2011Plenário. Como a realidade, via de regra, indica discrepância entre o registrado e o de fato contratado, entendemos que nem mesmo as meras vias da formalidade estão contempladas na realidade corrente." 


\title{
ISSN - 2447-178X
}

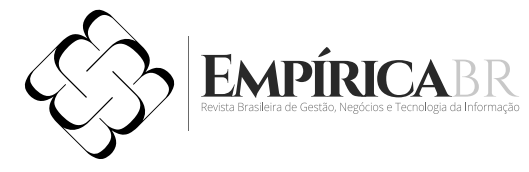

O planejamento prévio dos quantitativos e a sua relação com a economicidade foi objeto do seguinte destaque por parte do TCU:

\begin{abstract}
"Sabe-se que economia de escala atrela preço à quantidade demandada. Por isso, quanto maior o quantitativo licitado menor poderá ser o custo do produto, que tem por limite o chamado custo zero. A partir desse custo, o preço não varia em função da quantidade (BRASIL, 2010, p. 211)."
\end{abstract}

Sobre os possíveis benefícios da inclusão do mapa de consumo de períodos anteriores nas justificativas das quantidades solicitadas o licitante assim pontuou: "Não só para os licitantes, como para a Administração Pública, pois possibilita propostas realistas, mitigando riscos de quebra contratual que, por obviedade, tal discrepância pode proporcionar ao frustrar expectativa do contratado."

O licitante também foi questionado sobre quais são as principais dificuldades enfrentadas pelas empresas para cumprir os compromissos firmados e informou o seguinte:

\begin{abstract}
"A própria incerteza do consumo. Tal realidade impede programação para atendimento dos pedidos futuros, ocasionando custos operacionais e de capital com mercadoria adquirida/produzida pelo fornecedor, mas não contratada, bem como, pela outra mão, ocasiões em que pedidos muito volumosos são feitos pontualmente, dificultando a capacidade da empresa em atendê-los, já que a falta de embasamento para previsão de consumo contraindica ao fornecedor a manutenção de estoques significativos."
\end{abstract}

O licitante, ao receber a provocação para comentar sobre os tipos de estratégia desenvolvidas para enfrentar o cenário imprevisível vivenciado durante a validade de algumas Atas, mesmo após a recomendação do TCU para a inclusão do mapa de consumo, assim o fez:

\footnotetext{
"Consideramos existir apenas dois caminhos para superar essa dificuldade e conseguirmos nos preparar para uma tranquila execução contratual: A experiência de mercado e estudos prévios diretamente com o setor demandante ou mediante dados dos portais de transparência. Como em muitas categorias de fornecimento, há uma grande rotatividade de fornecedores que, em muitos casos, são inexperientes ou com baixa qualificação para atuação, e as informações advindas de experiência de mercado e de estudos prévios oriundos das devidas ferramentas não são amplamente praticadas, o que traz entraves ao mercado público, de modo geral."
}

O licitante comentou o seguinte sobre o fato de que o modelo de termo de referência mais utilizado pelos órgãos da Administração Pública Federal não contempla um item específico 
para a definição de "métodos e estratégias de suprimento" e se tal iniciativa poderia proporcionar benefícios:

\footnotetext{
"Sim, poderia. Muitas vezes a execução dos pedidos implicam inclusive em cessão de equipamentos, que muitas vezes não são abordados no instrumento convocatório. Isso gera inclusive a oferta de propostas inexequíveis, o que dá o caráter 'natimorto' às atas oriundas de propostas em tais condições."
}

O licitante, ao ser questionado sobre o serviço de frete utilizado na sua empresa, informou que utiliza os seguintes serviços: "próprios e terceirizados." Além disso, o licitante relatou que repassa os custos logísticos para o preço final dos produtos considerando um cenário bastante pessimista, conforme segue: "Os cálculos logísticos são onerados para a pior realidade possível."

Ao ser provocado a comentar sobre a utilidade da inclusão da previsão da frequência dos pedidos, bem como do lote mínimo do pedido para o planejamento do fornecedor, a seguinte análise foi apresentada pelo licitante: "Sim, extremamente úteis. 0 preço tende a ficar mais barato, pela confiança do proponente em seu cálculo de custos. Tal confiança não seria de fornecedor específico, o que acirraria a competição geral nas disputas."

Diante do diagnóstico apresentado, percebe-se que algumas melhorias poderiam ser facilmente implementadas para mitigar tais problemas, por meio do adequado controle de estoque com a criação de políticas bem definidas, contemplando o nível de estoque emergencial de cada produto, o ponto de ressuprimento, o lote mínimo de pedido, bem como a comunicação mais efetiva com o fornecedor.

\subsection{Análise da entrevista com o Agente de Controle Interno}

O Agente de Controle Interno ( $\mathrm{ACl}$ ) teceu os seguintes comentários sobre a exigência do TCU de obrigatoriedade da apresentação do mapa de consumo do ano anterior e a sua relação com um possível uso indiscriminado das Atas SRP:

“Na verdade, eu penso o seguinte, não é nem um uso indiscriminado das Atas, isso ocorreu por falta de planejamento dos órgãos. Eu entendi que essa exigência dos quantitativos, no qual o órgão precisa colocar o consumo do ano anterior ou até uma média de consumo dos anos anteriores é mais para justificar um pedido, porque estava ocorrendo uma grande falta de planejamento. Nós podemos ver isso no microcosmo da próprio órgão, porque os setores pedem as quantidades sem base em algum critério, porque a própria figura da Ata de Registro de Preços não obriga o órgão a contratar aquela quantidade e, assim, o setor solicitante não tem um planejamento para fazer aquela aquisição, então ela frustra a própria máquina administrativa que trabalha integrada para fazer aquele Pregão e, também, os fornecedores, porque participam do Pregão, trabalham para conseguir aquele preço. Alguns chegam a fazer um giro no estoque acreditando que irão vender e, na maioria, não vendem nem perto 


\section{ISSN - 2447-178X}

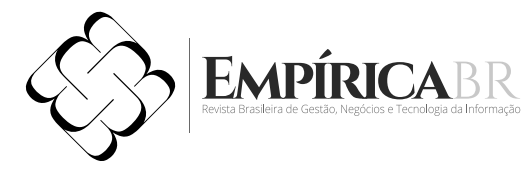

das quantidades informadas inicialmente. Então eu vejo mais como uma falta de planejamento do que uso indiscriminado da Ata. Em última instância podemos até falar em uso indiscriminado da Ata, mas é um uso indiscriminado gerado pela falta de planejamento."

O relacionamento entre o licitante e o órgão público, deve ser tradado de forma positiva, conforme leciona Fenili (2016, p. 93), já que "compradores e fornecedores não estão em disputa, mas sim em busca de uma condição em que ambos possam usufruir de vantagens e de estabilidade.

$\mathrm{O} \mathrm{ACl}$ ainda comentou o seguinte ao ser provocado sobre o fato de que a referida exigência do TCU não impedia que alguns os órgãos públicos informem que pretendem adquirir o mínimo de uma unidade por produto nos Pregões SRP, mesmo existindo um histórico de consumo bastante previsível e de fácil projeção que demonstre outra realidade, bem como a sua relação com uma possível tendência de gerar no licitante maior cautela quando da redução dos valores na fase de lances:

\footnotetext{
"Eu penso que depende muito do objeto. Se for um objeto do tipo itens de consumo para o almoxarifado o giro de estoque é mais rápido e o licitante pode baixar mais o preço, agora, material permanente, por exemplo, é diferente, e ele tem que pensar nisso sim, porque essa não obrigatoriedade de contratação, principalmente, para determinados tipos de objetos de licitação como o caso de material permanente faz o licitante pensar duas vezes antes de baixar muito o preço."
}

A ausência de uma formalização do nível de serviço logístico esperado do fornecedor no SRP foi tratada como segue:

\footnotetext{
“Eu tenho percebido pela minha experiência profissional na área de licitações, principalmente o seguinte: infelizmente tudo deve estar escrito. Então se não houver uma formalização, por escrito, editalícia e depois contratual dos níveis mínimos de serviços que devem ser prestados, eu vejo que fica difícil exigir, depois, da contraparte uma prestação de serviço condizente com a necessidade, não tem nem como o fiscal do contrato estabelecer um nível de serviço que ele pretende, principalmente porque a empresa, infelizmente, vai dizer que em nenhum momento foi estabelecido um nível mínimo para ela. A outra forma de se fazer seria realizando um acordo verbal entre as partes, posterior ao processo licitatório, para o alinhamento das necessidades, mas como não existe contrato verbal em Direito Administrativo a maneira mais segura de garantir a execução é a previsão editalícia dos níveis de serviço, inclusive com a sua transcrição para o instrumento contratual."
}

Sobre a possibilidade de definição, mesmo que em forma de previsão e não vinculante, do nível de serviço logístico e a sua possível influência na redução das ocorrências de inexecução ou execução 
parcial das obrigações da contratante e, por consequência, do número de processos administrativos para a apuração de faltas cometidas pelos fornecedores foi apresentado o seguinte tratamento:

\begin{abstract}
"A definição do nível de serviço logístico realmente minimiza a possibilidade de ocorrências para a Administração, porque a Administração vai ter tudo escrito e vai ter como cobrar e penalizar. O fornecedor já sabendo, desde o início, dessa regra do jogo, logicamente ele não quer ser penalizado, ele vai trabalhar para corresponder. Por isso é algo que eu sempre defendi nas licitações, porque é até uma forma isonômica de definir para os licitantes aquilo que você espera na prestação daquele serviço, e isso, a meu ver, já vai gerar um alinhamento do padrão de serviço da empresa e minimiza a probabilidade de futuros problemas na execução contratual."
\end{abstract}

Sobre o fato de que o modelo de Termo de Referência adotado pela grande maioria dos órgãos públicos federais não incluir um item específico para a definição de "métodos e estratégias de suprimento" e a possibilidade de inclusão do referido item no Termo de Referência foi informado o seguinte:

\begin{abstract}
“Eu vejo esse item de métodos e estratégias de suprimento como um item que não prejudica a formalização do Termo de Referência. Na verdade, é o estabelecimento de condições mínimas de entrega, a forma como o fornecedor vai entregar, onde vai entregar, desde que isso não vá de encontro ao previsto na Lei 8.666 , ou na Lei 10.520, ou qualquer outra legislação do Direito Administrativo, não acredito que tenha qualquer problema em criar esse item. Eu penso que seria importante porque já define onde vai ser entregue, isso tudo auxilia, também, o licitante para definir a questão do frete, porque isso impacta no preço dele, obviamente, então você dizer como quer que seja entregue, onde quer que ele entregue, acredito que não tem problema algum colocar isso no Termo de Referência e eu, como Agente de Controle Interno, tenho o entendimento de que não há nenhuma irregularidade."
\end{abstract}

Ao tratar sobre o procedimento anterior e seus reflexos para o alinhamento entre os fornecedores e a Administração, surgiu o seguinte comentário do $\mathrm{ACl}$ :

“Para mim esse procedimento apresenta reflexo positivo para a Administração, porque é o que eu defendo de que quando tudo já está escrito, a regra do jogo definida, como a Administração vai querer o serviço e como a empresa tem que se comportar auxilia o nosso trabalho, posteriormente, ao receber esse material ou serviço e, também, ao penalizar. Infelizmente, estamos percebendo que, hoje, essa penalização dos fornecedores está aumentando cada vez mais, não sei se por uma atuação mais formal ou uma atuação mais direta da Administração nessa questão do cumprimento 


\section{ISSN - 2447-178X}

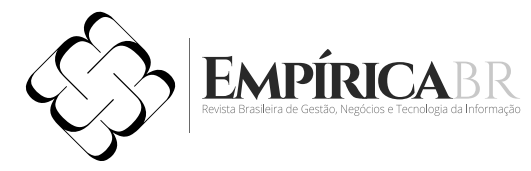

das regras, ou se realmente os fornecedores não estão atingindo os níveis exigidos pela Administração, mas a gente está vendo que o número de processos está aumentando e essa previsão do que se quer desde o início ajuda até na formação do processo de sanção."

$\mathrm{Na}$ visão do $\mathrm{ACl}$, a realização de um planejamento mais detalhado e o fornecimento de maiores informações sobre o histórico de consumo, a definição dos lotes mínimos e da frequência de pedido poderiam apresentar os seguintes reflexos na fase de lances e na redução dos preços:

“Com certeza se você detalhar de uma forma contundente, de uma forma razoável, de uma forma equilibrada, de uma forma fundamentada, se você colocar sua previsão de consumo, é lógico que o fornecedor pode se programar melhor para entregar aquele material, como ele vai entregar, quando ele vai entregar, ele vai ter uma ideia melhor disso, vai comprar esse material mais barato e vai repassar esse material mais barato. Ele vai poder 'brigar' com mais vontade na licitação porque ele sabe que se ganhar ele realmente vai entregar, tem isso também. Lógico que, como já comentado anteriormente, isso varia muito pelo objeto da licitação, mas de uma forma geral não tem como ver isso de uma forma negativa. Você prever o quanto vai consumir durante um ano de uma forma estruturada, planejada e como vai comprar isso auxilia a empresa, auxilia a própria Administração a planejar o seu consumo de estoque, auxilia de todas as maneiras. Eu vejo que o Tribunal de Contas da União está trabalhando de uma forma muito positiva nesse aspecto, gera mais dificuldade num trabalho inicial para o setor solicitante, mas isso ajuda até o próprio setor a realmente pedir aquilo que ele efetivamente sabe que vai comprar. 0 que agente via, antigamente, eram Pregões com quinhentos, seiscentos itens e o setor não comprava nem cinquenta, era só para cumprir a formalidade de ter preço registrado para tudo, isso era uma praxe na Administração. Isso ocorria desde o Ordenador de Despesa, até o responsável por elaborar o termo de referência no setor. Hoje, isso está mudando, porque os setores trabalham para comprar aquilo que realmente precisam. Tanto é que, se não houver uma expectativa de compra acima do limite do valor para dispensa, essa compra não será feita por Pregão, será por Dispensa, porque não justifica a feitura de um Pregão. Esse é o nosso posicionamento atual."

A seguinte reflexão foi apresentada pelo $\mathrm{ACl}$ ao ser provocado a comentar se, na prática, a Administração poderia estar pagando um preço maior pelos materiais por fornecer poucas informações para o dimensionamento da proposta do licitante:

"Realmente, se não há um dimensionamento da proposta de uma forma precisa, porque isso realmente gera uma imprevisibilidade no custo da aquisição desse 


\section{ISSN - 2447-178X}

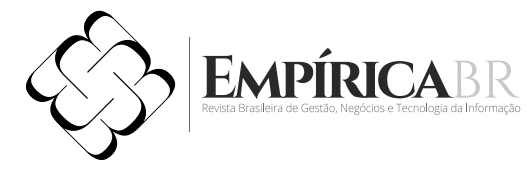

material, logicamente. Ora, no Pregão de permanente, se uma empresa se programa e ela compra para fornecer um material permanente caro e a Administração não compra, a empresa não pode entrar contra a Administração judicialmente, nem administrativamente, porque não houve a compra efetiva daquele material. Porém, é lógico que isso vai refletir negativamente para a própria Administração lá na frente porque essa empresa não vai mais participar, ou ela não vai se engajar na próxima disputa de preços. Você fazer um dimensionamento, um planejamento, auxilia de forma total para melhorar tanto para a empresa quanto para a Administração na redução dos preços."

A possibilidade da ocorrência de implicações jurídicas no caso de o gestor utilizar a faculdade legalmente prevista de não atingir as previsões iniciais sobre a intenção de adquirir lotes mínimos com uma frequência específica foi analisada como segue:

“Hoje, eu não tenho conhecimento de demanda judicial criada pelo 'descumprimento' por parte do gestor daquele planejamento de demanda inicial previsto no termo de referência, porque o Registro de Preços, ainda hoje, é, e isso está totalmente positivado no Direito Administrativo, o Registro de Preço não gera a obrigatoriedade de compra. Você pode ter um planejamento, mas isso não implica, necessariamente, que você tenha que comprar. Todos nós sabemos, afinal de contas, porque trabalhamos com dinheiro público, que esse orçamento é variável, haja vista, por exemplo, esse ano houve um decréscimo, um corte de quarenta por cento no orçamento, isso durante o ano, durante o 'rolar do jogo', e não tem como a gente saber. Então, assim, o gestor faz esse planejamento, mas ele pode não receber aquele recurso que ele achou que receberia, isso tudo, infelizmente, é variável. Pelo histórico podemos fazer um planejamento com base no que foi consumido, mas e o ano que vem? Logicamente que vamos tentar trabalhar para cumprir o planejamento, mas, se não puder, o Registro de Preço nos ampara totalmente em relação a isso e eu vejo totalmente descabível uma demanda judicial de uma empresa contra um órgão público que não 'cumpriu' o planejamento inicialmente previsto para um Pregão de Registro de Preço."

A possível relação de causa/efeito entre a adoção de medidas de planejamento, que potencialmente poderiam reduzir os custos das aquisições e, também, minimizar a abertura de processos administrativos visando apurar inexecução ou execução parcial das entregas e o Princípio da Eficiência foi comentada da seguinte forma pelo ACl:

“Certamente a adoção de medidas que possam reduzir o número de processos de apuração de irregularidade por parte do fornecedor são muito relevantes para prestigiar o princípio da eficiência, porque, vamos pensar, o gestor que está trabalhando bem no 


\section{ISSN - 2447-178X}

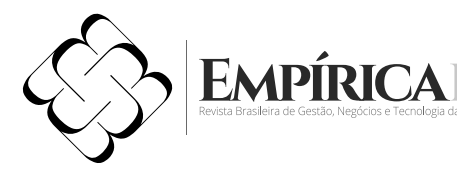

planejamento vai evitar com que, futuramente, a gente pegue um fornecedor ruim, pelo menos minimiza o risco e reduz as chances de ter processos administrativos nos quais alguns funcionários tenham que parar para conduzir um processo administrativo de apuração de irregularidade, tudo isso, no final, implica na eficiência. Trabalhar com um planejamento inicial bem feito sempre vai melhorar a eficiência da Administração, porque vai fazer o gestor trabalhar, primeiramente, focado naquilo que ele planejou desde o início, e depois ele não vai perder tempo tendo que dividir a atenção entre trabalhar na seção e trabalhar fazendo um processo administrativo. Então com certeza ajuda."

\section{CONCLUSÃO}

Tendo em vista os argumentos apresentados, verifica-se a real possibilidade de inclusão das informações relativas ao lote mínimo de pedido e sobre a frequência de pedido para uma gama de produtos. Entretanto, a determinação de quais produtos podem ser objeto de tais especificações dependerá de uma classificação dos produtos em duas categorias, a saber: produtos que apresentam previsão de consumo estável e produtos que apresentam previsão de consumo variável. Posteriormente, o órgão licitante poderá realizar estudos para a determinação dos níveis de estoque ideais e, assim, definir o lote mínimo de pedido e sua frequência.

As informações mencionadas anteriormente, podem influenciar os licitantes a oferecerem lances mais vantajosos para a Administração nas licitações, já que, embora não sejam vinculantes para o gestor público, por conta da própria natureza do Sistema de Registro de Preços (SRP), certamente deverão proporcionar ao licitante a possibilidade de planejar seus estoques e o nível de serviço logístico necessário para o atendimento das demandas, bem como calcular e projetar o custo logístico que será repassado ao preço final do produto.

Assim, as intervenções indicadas a seguir devem ser compreendidas dentro de um contexto de limitações de profundidade, amostragem e extensão do presente trabalho. Entretanto, mesmo tratando-se de uma pesquisa inicial, o levantamento de aspectos que carecem de melhorias nos processos de aquisição poderá despertar nos gestores da organização militar o interesse em incentivar novas investigações visando o aumento da eficiência e da economicidade na utilização dos recursos financeiros disponíveis, até mesmo com a contratação de consultorias especializadas.

Sendo assim, recomenda-se que o órgão público em análise realize estudos prévios para a definição dos quantitativos máximo e mínimo para cada produto a ser licitado, considerando o histórico de consumo. Além disso, deve-se considerar a possibilidade de implementação de práticas adequadas de gestão de estoque para que seja possível definir com maior precisão a frequência de pedido, já que tais informações são essenciais para que os futuros fornecedores apresentem preços nas licitações compatíveis com o potencial de consumo do órgão com base nos dados repassados pela Administração. 


\section{ISSN - 2447-178X}

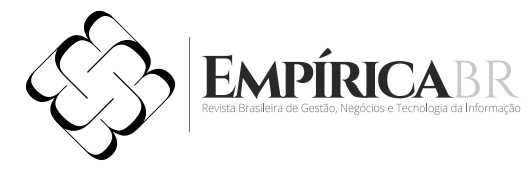

Adicionalmente, pode-se indicar a utilização de fatores de ressuprimento como parâmetro de otimização das aquisições, tais como o consumo médio mensal, tempo de aquisição, intervalo de aquisição, estoque mínimo ou de segurança, estoque máximo, ponto de pedido e quantidade a ressuprir, nos termos da Instrução Normativa № 205, de 08 de abril de 1988, ainda vigente.

Finalmente, deve-se ressaltar que haverá continuidade das pesquisas iniciadas no trabalho ora apresentado, inclusive com o aprofundamento das análises, notamende pelo fato de que as sugestões de melhoria apresentadas serão, posteriormente, implementadas na organização militar pesquisada. Logo, mediante avaliação positiva dos resultados obtidos, deverá haver a divulgação das técnicas aplicadas para que os novos procedimentos sejam adotados em outras organizações militares.

\section{REFERÊNCIAS}

1. BALLOU, Ronald H. Gerenciamento da cadeia de suprimento. 5. ed. São Paulo : Bookman, 2006.

2. Logística empresarial: transportes, administração de materiais e distribuição física. 1 ed. São Paulo: Atlas, 2015.

3. Brasil. Advocacia-Geral da União (AGU). Consultoria-Geral da União. Manual de licitações e contratações administrativas. Brasília: AGU, 2014. 460 p. Disponível em: <http://www.agu.gov.br/page/ download/index/id/28095554>. Acesso em 04 nov. 17.

4. BRASIL. Constituição da República Federativa do Brasil: Texto constitucional promulgado em 5 de outubro de 1988, com as alterações adotadas pelas Emendas Constitucionais no 1/92 a 56/2007 e pelas Emendas Constitucionais de Revisão nº 1 a 6/94. 4. Brasília: Diário Oficial da União,05 out. 1988. Disponível em: <https://www.planalto.gov.br/ccivil_03/constituicao/constituicao.htm>. Acesso em: 04 nov. 2017.

5. BRASIL. Decreto $\mathbf{n}^{\circ} \mathbf{5 . 4 5 0}$, de 31 de maio de 2005. Regulamenta o pregão, na forma eletrônica, para aquisição de bens e serviços comuns, e dá outras providências. Brasília: Diário Oficial da União, 01 jun. 2005. Disponível em: <http://www.planalto.gov.br/ccivil_03/_ato2004-2006/2005/decreto/d5450. htm>. Acesso em: 04 nov. 2017.

6. BRASIL. Decreto $\mathbf{n}^{\circ} \mathbf{7 . 8 9 2}$, de 23 de janeiro de 2013. Regulamenta o Sistema de Registro de Preços previsto no art. 15 da Lei n 8.666, de 21 de junho de 1993. Brasília: Diário Oficial da União, 23 jan. 2013. Disponível em: <http://www.planalto.gov.br/ccivil_03/_ato2011-2014/2013/decreto/d7892. htm>. Acesso em: 04 nov. 2017.

7. BRASIL. Instrução Normativa $\mathbf{N}^{\circ} \mathbf{2 0 5}$, de 08 de abril de 1988. Racionaliza sobre minimização de custos do uso de material no âmbito do SISG através de técnicas modernas que atualizam e enriquecem essa gestão. Brasília: Diário Oficial da União, 11 abr. 1988. Disponível em: <https:// www.comprasgovernamentais.gov.br/index.php/legislacao/instrucoes-normativas/442-instrucaonormativa-n-205-de-08-de-abril-de-1988>. Acesso em: 04 nov. 2017. 
8. BRASIL. Lei n. 8.666, de 21 de junho de 1993. Regulamenta o art. 37, inciso XXI, da Constituição Federal, institui normas para licitações e contratos da Administração Pública e dá outras providências. Brasília: Diário Oficial da União, 22 jun. 1993. Disponível em: <http://www.planalto.gov.br/ccivil_03/leis/ L8666cons.htm>. Acesso em: 04 nov. 2017.

9. BRASIL. Lei $\mathbf{n}^{\circ} \mathbf{1 0 . 5 2 0}$, de $\mathbf{1 7}$ de julho de 2002. Institui, no âmbito da União, Estados, Distrito Federal e Municípios, nos Termos do Art. 37, Inciso XXI, da Constituição Federal, Modalidade de Licitação Denominada Pregão, Para Aquisição de Bens e Serviços Comuns, e Dá Outras Providências. Brasília, DF, Disponível em: <http://www.planalto.gov.br/ccivil_03/leis/2002/l10520.htm>. Acesso em: 04 nov. 2017.

10. BRASIL. Tribunal de Contas da União. Licitações e contratos: orientações e jurisprudência do TCU. - 4. ed. rev., atual. e ampl. - Brasília: TCU, Secretaria-Geral da Presidência: Senado Federal, Secretaria Especial de Editoração e Publicações, 2010. Disponível em:<http://portal.tcu.gov.br/lumis/ portal/file/fileDownload.jspinline=1\&fileld=8A8182A24D6E86A4014D72AC81CA540A> Acesso em 04 nov. 17.

11. CARRIJO, Maria Tereza Dutra; SANTOS, Márcia Walquiria Batista dos (org.). Licitações e Contratos: roteiro prático. 2. ed. Rev. e ampl. - São Paulo: Malheiros, 2001.

12. CASTOR, Belmiro Valverde Jobim; ZUGMAN, Fábio. Dicionário de Termos de Estratégia Empresarial. São Paulo: Atlas, 2008.

13. CHIAVENATO, Idalberto; SAPIRO, Arão. Planejamento Estratégico. 2. ed. Rio de Janeiro: Elsevier, 2009.

14. FARIA, Ana Cristina de; COSTA, Maria de Fátima Gameiro da. Gestão de custos logísticos. 1. ed. São Paulo: Atlas, 2015.

15. FENILI, Renato Ribeiro. Gestão de Materiais. 2. ed. Brasília: Enap, 2016.

16. FERNANDES, Jorge Ulysses Jacoby. Sistema de Registro de Preços e Pregão Presencial e Eletrônico. 5. ed. Belo Horizonte: Fórum, 2011.

17. FIGUEIREDO, Kleber Fossati; FLEURY, Paulo Fernando; WANKE, Peter (org.). Logística e gerenciamento da cadeia de suprimentos: planejamento do fluxo de produtos e dos recursos. 1. ed. 3. São Paulo: Atlas, 2006.

18. GIL, Antônio Carlos. Métodos e Técnicas de Pesquisa Social. São Paulo: Editora Atlas, 2008.

19. GOMES, Eugênio Maria; MORGADO, Almir. Compêndio de Administração. Rio de Janeiro: Elsevier, 2012.

20. JUSTEN FILHO, Marçal. Comentários a lei de licitações e contratos administrativos. 17. ed. São Paulo: Editora Revista dos Tribunais, 2016. 


\section{ISSN - 2447-178X}

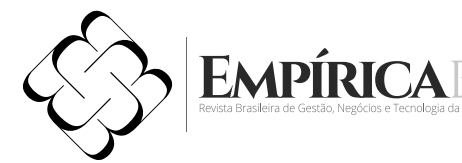

21. KANAANE, Roberto; FIEL FILHO, Alécio; Ferreira, Maria das Graças. Gestão pública: planejamento, processos, sistemas de informação e pessoa. São Paulo: Atlas, 2010.

22. LAKATOS, Eva Maria; MARCONI, Marina de Andrade. Técnicas de pesquisa: planejamento e execução de pesquisas, amostragens e técnicas de pesquisa, elaboração, análise e interpretação de dados. 7. ed. São Paulo: Atlas, 2012.

23. MEIRELLES, Hely Lopes. Direito Administrativo Brasileiro. - 42. ed. Atual até a Emenda Constitucional 90, de 15.9.2015. São Paulo: Malheiros, 2016.

24. OLIVO, Luis Carlos Cancelier de. Licitações, contratos e convênios. Florianópolis: Departamento de Ciências da Administração / UFSC; [Brasília]: CAPES: UAB, 2011.

25. ROSA, Rodrigo de Alvarenga. Gestão logística. - 2. ed. Florianópolis: Departamento de Ciências da Administração / UFSC; [Brasília]: CAPES: UAB, 2012.

26. SEVERINO, Antônio Joaquim. Metodologia do Trabalho Científico. - 23. ed. São Paulo: Cortez, 2007.

27. SILVA, Magno Antônio da. 0 conceito de eficiência aplicado às licitações públicas: uma análise teórica à luz da economicidade. Revista do TCU, Brasília, DF, ano 40, n.113, p.71-84, set. /dez. 2008. Disponível em: <https://portal.tcu.gov.br/biblioteca-digital/revista-do-tcu-n-113-set-dez-2008.htm>. Acesso em 04 nov. 2017.

28. ZANELLA, Liane Carly Hermes. Metodologia de estudo e de pesquisa em administração. Florianópolis: Departamento de Ciências da Administração / UFSC; [Brasília]: CAPES: UAB, 2009. 